obtaining groups of Native and European children exactly comparable from the point of view of social and economic conditions and schooling facilities but he attemps to allow for these factors in his evaluation of his results. The tests used were: a drawing test with the Moede double-handle apparatus, a mirror drawing test, a sorting test, and a maze test.

In every test the average performance of the European children outstrips that of the Native children. The difference is least in the sorting and maze tests, and after practice the Native children attain a level of performance very close to that of the European children. Dr. van Rensburg's conclusion is therefore based, in effect, on only two tests. His results with respect to these are conclusive. The Native pupils undoubtedly fall far below the European children both in initial performance, their rate of improvement, and the level attained after practice.

To any one familiar with similar work that has been done in America these results will not be unexpected, and Dr. van Rensburg's general inference will remain as unconvincing as similar inferences that have been drawn by some American psychologists and have been severely criticized by others. It is well known that satisfactory tests of ability must consist of batteries, not single tests. Their validity and reliability must be established before they can be of any use, and we must know what exactly they are testing. Dr. van Rensburg gives no information on these points. It is probable, for instance, that his two critical tests involve a considerable element of manual dexterity. He does not apply modern statistical and analytical techniques to investigate this; he is content to speak sweepingly of 'learning ability'. It is significant, in this connexion, that he found a group of Native children from superior homes to approximate more closely to the performance of the European children than the whole Native group. 'Environmental' factors thus obviously influence the performances he tested. (Contributed by Dr. M. Fories.)

\title{
A Report on Achimota.
}

IN 1938 the Governor of the Gold Coast appointed a Committee 'to inquire into all matters relating to the system of education obtaining in the College', and to endeavour to ascertain 'whether Achimota is fulfilling the aims and objects for which it was established, and to decide whether, in the light of experience and existing conditions, those aims and objects should now be modified'. Stress was also laid on the desirability of investigating the place of West African vernaculars in higher education.

Achimota occupies an outstanding position in West African education; it is almost unique in the whole of Africa in that it shows what can be done under exceptionally favourable conditions for the promotion of African education. Only a colony with a national wealth and a population so far advanced as 
that of the Gold Coast could undertake to establish an institute on analogous lines.

The special aim of Achimota College is to provide an education which gives the pupil free access to European knowledge and culture and which at the same time does not neglect the cultural heritage of his own people, a combination which is not easy to fulfil and which almost inevitably leads to a preponderance of the European side. The school is also unique in two other respects: it covers all stages of education from the kindergarten to university study, and it is completely co-educational, offering an education on equal terms to boys and girls up to the beginning of University work. The classes in all subjects, except those which are peculiarly the field of one sex or the other, e.g. engineering for boys and domestic science for girls, are mixed, and all social activities except games are shared.

At the time of the Inspection the kindergarten was attended by 32 boys and 28 girls between the ages of 6 and 9 years. The course lasts three years; all teaching is done in the vernaculars, viz. Twi, Fante, Ga, and Ewe. That there is a demand for a kindergarten on the part of certain urban Africans is shown by the fact that the applications for admission exceed the vacancies. On the other hand, some experienced Africans, including some who had been educated at Achimota and some who had begun in the kindergarten, expressed to the Inspectors considerable doubt as to whether it was good for African children to be taken away from their families at so early an age. Though the teaching is done in the vernacular, the atmosphere of the kindergarten is predominantly European, and the children are in danger of losing their association with the established customs of their own people. There may be a need for a kindergarten in certain African areas, but the need is certainly not pressing, and many of the children could certainly be accommodated in the day schools of their home villages or, in exceptional cases, in simple local infant schools especially established for the purpose. The Inspectors are of opinion that if the chief function of Achimota is to provide higher education, then this is a scheme into which neither the kindergarten nor the Lower Primary Department will fit easily. It is therefore suggested that both should gradually be dropped.

The Lower Primary Department was composed of 54 boys and 38 girls between the ages of 7 and I I years. The department provides a three-year course of education corresponding to Standards I, II, and III in the Government schools. The three forms are again subdivided into seven classes, of which those of the first and second years are divided on a basis of language and those of the third year according to ability. In 1932 the proportion of African teachers to European teachers in the kindergarten and Lower Primary Department was $4: 7$, but a policy of steadily increasing the proportion of Africans has been pursued so that now there are I 2 Africans to 2 Europeans. 
The vernaculars are the medium of instruction almost throughout the Lower Primary course. English is taught as a foreign language, except that during the last year there is a transition stage during which the children are given an increasing proportion of their lessons in English as a preparation for the higher classes.

Written work in English is not begun until the third year, and is then restricted to short exercises. The teachers are Africans. Other subjects taught are arithmetic, geography, history and civics, nature study, handwork, needlework, music, and physical training. Handwork is at present in a transitional stage, passing from the older type of 'hand and eye' training to the freer use of materials, leading, at the end of the course, to a beginning of craftsmanship. Pottery is encouraged, so are basketry and raffia work. They are not yet free from the European conceptions under which they started, but gradually the children learn to use local dyes and to make patterns, shapes, and objects expressive of their own native tastes and purposes. The geography syllabus stresses the human aspect of the subject, and in the observation of natural phenomena and in map-making is linked up with local nature-study.

The Middle (Upper Primary) School was composed of 75 boys and 68 girls, the ages of the pupils ranging from I I to 17 years. It offers a fouryear course, corresponding to Standards IV-VII of Government schools. The age distribution in this school is wide. There are no less than 32 children of 16 years of age and over. This unsatisfactory state of things can only gradually be overcome, by standardizing the age of entry and the attainments at entry. The Middle School is recruited mainly by promotions from the Lower Primary Department, but children from other schools are also admitted. The curriculum consists of English, arts and crafts (including woodwork and housecraft), arithmetic, history and civics, geography, music, physical training, science and hygiene, scripture, and vernacular languages. All the instruction is in English except during the bi-weekly vernacular periods, when the children are re-classified into four language groups. No less than 32 teachers take part in instructing these six classes of children.

The Teacher-Training Department. When Achimota was founded it took over the Government Training College for Men Teachers which up to then had existed in Accra. At the time of the Inspection the students in this Department were 86 boys and 66 girls. Their ages vary from 14 years to 24, but the range is gradually decreasing. The College trains teachers to teach all subjects to all children from the lowest class of infants to Standard VII, and in addition the men are trained to teach some woodwork and agriculture, and the women to teach domestic science. This is certainly a wide field, hardly equalled by any corresponding college in Europe. The course is a four-year one, the first and second years being devoted entirely to the consolidating and broadening of the students' own education. Emphasis is 
laid on oral English. Agriculture and hygiene are included. In the third and fourth years the study of the theory of education and the practice of teaching are added, but none of the other subjects is dropped, though less time is given to English, mathematics, and music. In the third year of their training the students do six weeks' practice in schools in Accra and in the fourth year, twelve weeks, in fortnightly periods. Moreover, during one term in his third and fourth year each student belongs to a demonstration group of eight students in the charge of one of the education tutors. Demonstration lessons are planned by the group and given to classes in Achimota Middle and Lower Primary Schools. Other demonstration lessons are given by the education staff in the schools in which the students are doing school practice. These lessons are watched by all the students in that school and are given in conditions similar to those in which the students will eventually have to teach. Only those students who speak the local vernacular, $\mathrm{Ga}$, can practise teaching younger children in the Accra schools, but vernacular training camps are held during one vacation week, and all the Ewe, Twi, and Fante students are thus enabled to practise in their own mother tongue.

The Secondary Department was attended by 153 boys and 27 girls between the ages of I 4 and I9 years. The goal of this Department is the Cambridge School Certificate Examination; practically the whole of the school time of the higher forms is devoted to working for this Examination, and owing to the difficulty of working in English, and their lack of practice in independent reading, the pupils depend very much on instruction by their teachers. The Inspectors see the chief weakness of the existing organization in the lack of adequate provision for those boys and girls whose talents are more of the practical than of the academic kind. 'There is a real need of a secondary course with a technical and practical bias, not necessarily (or probably) leading to a School Certificate Examination.' A feature of the course is that it includes Latin. Though it may seem somewhat out of place in an African school, 'there is at present a real demand for it on the part of pupils and parents, who regard it as one of the distinctive elements in the English education which they desire to imitate, and even if this consideration must carry less weight at a time when the place of Latin in English education itself is becoming less conspicuous, it would be a mistake to dispense with a subject in which many students at Achimota evidently acquire a keen interest for its own sake, and which, as it is treated here, certainly helps them towards the formation of mental habits of permanent value'.

The four vernacular languages continue to be studied throughout the School and College. The teaching is mainly in the hands of African masters, but several of the European staff are able to take part both in supervision and examination. A considerable proportion of the School Certificate 
candidates offer one or other of the languages, and the results are generally satisfactory.

The Commercial Class. This course aims at preparing students for the Separate Subjects Certificates issued by the London Chamber of Commerce; it is not intended to be strictly vocational, but to assist in giving those students who contemplate a business career a good general education. Practical experience is gained by the students in the College Shop, where, under the general supervision of the teacher of the Elements of Commerce, they serve in turn at the counter and learn to handle real accounts.

The University Courses. These are intended for students who wish to prepare for any of the following external examinations of the University of London: Intermediate Arts, or Science, or Agriculture; the first examination for medical degrees; and the Intermediate and Final B.Sc. degree examinations in Engineering. Before he can be admitted to any of these courses a student must have passed or obtained exemption from the London Matriculation Examination. Students who wish to enter the Engineering course are required as a condition of acceptance to spend a preliminary period of six weeks in engineering works and are not accepted unless they are favourably reported on by the Works Manager.

Of the 33 students in the University Classes, 8 were previously educated at Achimota, while the rest came from other schools in the Gold Coast and in Nigeria. In the years 1932 to 1937,32 students passed out of the University classes. From such information as is available in regard to the subsequent careers of these students it would appear that I I have entered the teaching profession, 2 are in the Government Printing Press, and 2 others in the Civil Service. Two Engineering Students have entered the service of the Government Railways Departments, and 3, who did not complete the Engineering course, were being trained as assistant mill shift bosses in Konongo Gold Mines Ltd. Eight students proceeded to Great Britain for further studies, 5 among them being medical students.

\section{The Practice of 'Uvaisi' among the Ovimbundu.}

[Translator's note. The account of marriage customs among the Ovimbundu would not be complete without mention of the licit sexual telation known as waisi. Uvaisi is a sort of trial martiage having a certain counterpart in the New England colonial custom known as 'bundling'. It does not differ essentially from some forms of modern excitement known in recent American as ' petting'. Apparently the word waisi is related to the word for marriage, uwala. The ending isi indicates the causative stem; in this case it would mean that-which-causes-marriage. It is a common thing for the $l$ to be elided in Umbundu, thus walisi is waisi. It is very common to say zwaisi waño; waño means common, ordinary, inferior. I have asked, 'Why is it waño?' No one knows. The early missionaries in seeking for a word to indicate illicit sexual relations and sexual misbehaviour hit on this word and

$$
\mathrm{k} \mathbf{k}
$$

